\title{
The Effects of Cyanide on the Growth and Respiration of Enterobacter aerogenes in Continuous Culture
}

\author{
By N. PORTER, $\dagger$ J. W. DROZD* AND J. D. LINTON \\ Shell Research Limited, Sittingbourne Research Centre, Sittingbourne, Kent, ME9 8AG, U.K.
}

(Received 15 March 1982; revised 27 June 1982)

\begin{abstract}
The effect of cyanide on the physiology of lactate- and oxygen-limited Enterobacter aerogenes NCTC 10336 was studied in chemostat culture $\left(D=0 \cdot 1 \mathrm{~h}^{-1}\right)$. In the absence of cyanide, the molar growth yield from oxygen $\left(Y_{\mathrm{O}_{2}}\right)$ under oxygen limitation was $60 \%$ of the carbon-limited value. A similar decrease in yield was observed in a lactate-limited culture (excess oxygen) which was continuously fed low concentrations of potassium cyanide. The cultures with the lower growth yields possessed respiratory systems less sensitive to inhibition by cyanide. This was particularly marked in cultures grown in the presence of cyanide. Increased cyanide resistance was associated with an increase in the concentration of a cytochrome oxidase tentatively identified as a $d$-type and the appearance of additional cytochromes tentatively identified as $b$ type.
\end{abstract}

\section{INTRODUCTION}

Cyanide is a potent inhibitor of the activities of a large number of enzymes (Dixon \& Webb, 1964). It is particularly noted for its reactivity with haemoproteins such as the cytochrome oxidases. Consequently, the cytochrome composition of bacteria exhibiting decreased respiratory sensitivity to cyanide has been examined in detail and the area has been reviewed (Knowles, 1976). These studies suggest that there is a correlation between increased resistance to cyanide and the presence of cytochrome oxidase $d$. This oxidase is normally absent or only present in low concentrations in aerobic exponentially growing cultures. However, its formation is stimulated under these conditions when cyanide is included in the growth medium (Arima \& Oka, 1965; Oka \& Arima, 1965; Ashcroft \& Haddock, 1975). Linton et al. (1976) showed that great care is needed in the interpretation of cyanide inhibition data; in Beneckea natriegens the apparent degree of resistance of respiration to cyanide inhibition was related to the respiration rate.

Some species of the Enterobacteriaceae, including Enterobacter aerogenes, exhibit cyanideresistant growth (Møller, 1954; Munson, 1974; Porter \& Knowles, 1979). Enterobacter aerogenes NCTC 10336 forms cytochromes $a_{1}, d$ and $o$ during aerobic batch growth, with increased synthesis of cytochrome $d$ when cyanide is included in the medium (Porter, 1979). To examine cyanide resistance in this organism, cultures were grown continuously, so that growth parameters could be varied and any changes in cyanide sensitivity correlated with changes in cytochrome composition without secondary effects of cyanide on, for example, the growth rate. Meyer \& Jones (1973) have suggested that the existence of multiple oxidases in bacteria is associated with different efficiencies of oxidative phosphorylation. Measurements of growth yields (particularly with respect to oxygen, $Y_{\mathrm{O}_{2}}$ ) were therefore routinely carried out.

Cyanide is present in several types of aqueous industrial effluents which are subsequently biotreated. It is, therefore, of practical interest to study the effects of cyanide on an aerobic organism as a model of such a system. Of course, in practice the biotreater will contain a mixed culture, but by studying one type of organism some data of general relevance to the aerobic biotreatment of such wastes may be obtained.

$\dagger$ Present address: Glaxo Group Research Ltd, Greenford Road, Greenford, Middlesex, UB6 0HE, U.K. 


\section{METHODS}

Organism. Enterobacter aerogenes NCTC 10336 was obtained from Dr J. V. Lee, Maidstone Public Health Laboratory. The organism was maintained by monthly subculture on nutrient agar slopes.

Medium. The growth medium contained per litre: $\left(\mathrm{NH}_{4}\right)_{2} \mathrm{SO}_{4}, 2.97 \mathrm{~g} ; \mathrm{H}_{3} \mathrm{PO}_{4}, 1.089 \mathrm{~g} ; \mathrm{MgSO}_{4} .7 \mathrm{H}_{2} \mathrm{O}$, $0.0988 \mathrm{~g} ; \mathrm{CaCl}_{2} .2 \mathrm{H}_{2} \mathrm{O}, 0.0148 \mathrm{~g} ; \mathrm{KCl}, 0.746 \mathrm{~g} ; 0.1 \mathrm{M}-\mathrm{FeSO}_{4} .7 \mathrm{H}_{2} \mathrm{O}, 0.33 \mathrm{ml} ; 5 \mathrm{ml}$ of a trace elements solution containing per litre: $\mathrm{ZnSO}_{4} .7 \mathrm{H}_{2} \mathrm{O}, 0.287 \mathrm{~g} ; \mathrm{MnSO}_{4} .4 \mathrm{H}_{2} \mathrm{O}, 0.233 \mathrm{~g} ; \mathrm{H}_{3} \mathrm{BO}_{3}, 0.0618 \mathrm{~g} ; \mathrm{CuSO}_{4} .5 \mathrm{H}_{2} \mathrm{O}, 0.125 \mathrm{~g}$; $\mathrm{Na}_{2} \mathrm{MoO}_{4} .2 \mathrm{H}_{2} \mathrm{O}, 0.0484 \mathrm{~g} ; \mathrm{CoCl}_{2} .6 \mathrm{H}_{2} \mathrm{O}, 0.0476 \mathrm{~g} ; \mathrm{KI}, 0.083 \mathrm{~g} ; 1 \mathrm{M}-\mathrm{H}_{2} \mathrm{SO}_{4}, 1.0 \mathrm{ml}$. Sodium D,L-lactate $(70 \%$, $\mathrm{w} / \mathrm{v}$, solution) was added to the bulk medium to give a concentration of $5 \cdot 7 \mathrm{~g}^{-1}$ which provided carbon-limited growth. The bulk medium, the $\mathrm{FeSO}_{4}$ and the sodium lactate solutions were sterilized separately and mixed aseptically when required. Sterilization was achieved by autoclaving at $121^{\circ} \mathrm{C}$, apart from the $\mathrm{FeSO}_{4}$ solutions which were sterilized by filtration using Millipore $0.45 \mu \mathrm{m}$ membrane filters.

Solutions of $\mathrm{KCN}$ for fermenter studies $\left(0.65 \mathrm{~g} \mathrm{l}^{-1}\right.$ in distilled water) were sterilized by filtration. The cyanide solution was stabilized by maintaining it in an ice bath and was replaced daily with a fresh solution.

Fermenter cultures. A Biotec fermentation vessel (LKB) was used, which consisted of a Pyrex glass cylinder fitted with stainless steel head and base plates. The head plate was modified such that agitation was achieved by a direct drive single six-bladed impeller (Maxted \& Wayne Smith, 1974). The culture was stirred at a speed of 600 r.p.m. and the working volume was kept constant at approximately 21 by means of a stainless steel overflow tube connected to the effluent collecting vessel by silicone rubber tubing. Medium was pumped into the fermenter from a 301 reservoir with a peristaltic pump (Watson Marlow Ltd, Falmouth, Cornwall). By using larger diameter silicone tubing the same pump was used to remove bacterial culture from the fermenter via the overflow tube. Cyanide was pumped into the fermenter from a separate $500 \mathrm{ml}$ vessel using an LKB Varioperpex 12000 peristaltic pump to give a calculated concentration of $200 \mu \mathrm{M}$ in the inflowing medium. The temperature was maintained at $30^{\circ} \mathrm{C}\left( \pm 0.5^{\circ} \mathrm{C}\right)$ using a $0-50^{\circ} \mathrm{C}$ potentiometric indicator/controller (Fielden Electronics Ltd) fitted with a platinum resistance thermometer that controlled the flow of hot and cold water through two separate finger heat exchangers projecting into the fermenter. Culture $\mathrm{pH}$ was held constant at $7.0 \pm 0.05$ by the addition of $0.5 \mathrm{M}$ $\mathrm{NaOH} / 0.5 \mathrm{M}-\mathrm{KOH}$ or $1 \mathrm{M}-\mathrm{HCl}$ in response to a signal from a pH titrator (Titrator II, Radiometer A/S, Endrupues, Copenhagen, Denmark) connected to a steam sterilizable combined glass/reference electrode (Radiometer, Copenhagen). The culture was aerated and the dissolved oxygen tension (DOT) controlled by bubbling sterile air or various air/nitrogen mixtures at $2.01 \mathrm{~min}^{-1}$ through the base of the fermenter immediately below the impeller blades. The gas flow rate into the fermenter was measured using a rising soap film column. The DOT was measured with a galvanic cell oxygen probe (L.H. Engineering Co. Ltd, Stoke Poges, Buckinghamshire) connected in series with a $5 \mathrm{k} \Omega$ variable potentiometer. The probe was calibrated in uninoculated growth medium by bubbling air through the fermenter overnight and adjusting the recorder to read $100 \%$, indicating air saturation. The zero reading was checked by turning off the air supply and bubbling nitrogen through the vessel.

Oxygen, carbon dioxide and nitrogen in the inlet and outlet gas streams were measured by a fully automatic gas chromatograph system. The system relies on the separation of gases by a modification of the method of Deans et al. (1971).

Assays. Cyanide was assayed according to the method of Epstein (1947). Lactic acid was assayed as its trimethylsilyl derivative by GLC using a Varian aerograph series 1800 chromatograph containing a glass column of $5 \% \mathrm{JXR}$ on Porapak Q (Field Instruments Ltd, Richmond, Surrey). The oven and flame ionization detector temperatures were set at $120^{\circ} \mathrm{C}$ and $200^{\circ} \mathrm{C}$, respectively. Acetic acid was also assayed by GLC using a column of Porapak Q and an oven temperature of $190^{\circ} \mathrm{C}$.

Carbon analyses were carried out using a Beckman model 915 total organic carbon analyser. The carbon content of the cells was calculated from the difference between whole culture carbon and that of a Millipore $(0.45 \mu \mathrm{m}$ pore size) filtrate of the culture.

The percentage of elemental carbon, hydrogen and nitrogen in a freeze-dried sample of bacteria was determined using a Hewlett-Packard $185 \mathrm{C}, \mathrm{H}$ and $\mathrm{N}$ analyser according to the manufacturer's instructions.

Determination of the effect of cyanide on bacterial respiration. Bacteria harvested from the fermenters were washed once in basal medium free of carbon and nitrogen sources at $\mathrm{pH} 7.0$ and were resuspended in the same medium to give a concentration of approximately $6 \mathrm{~g}$ bacterial carbon $\mathrm{1}^{-1}$. Respiration was measured polarographically at $30^{\circ} \mathrm{C}$ in the chamber of an oxygen-electrode respirometer (Rank Bros, Bottisham, Cambridge). The incubation medium consisted of $4.8 \mathrm{ml}$ carbon- and nitrogen-free growth medium, $\mathrm{pH} 7.0$, containing an appropriate concentration of cyanide. The bacterial suspension $(100 \mu \mathrm{l})$ was injected into the electrode chamber and incubated with cyanide for $2 \mathrm{~min}$ prior to initiation of oxygen uptake by addition of $100 \mu \mathrm{l} 20 \mathrm{mM}$-sodium L-lactate. Results are expressed as $\mathrm{mmol} \mathrm{O}_{2}$ (g bacterial dry $\mathrm{wt}^{-1} \mathrm{~h}^{-1}$.

Determination of apparent $K_{\mathrm{m}}$ values for the oxidation of sodium D- and L-lactate. Apparent $K_{\mathrm{m}}$ values were determined by measuring the initial rates of oxygen uptake by harvested bacteria in the presence of different concentrations of oxidizable substrate (Jones \& Carrington, 1972).

Determination of cytochrome spectra. Cytochrome spectra of whole bacteria were recorded at room and liquid 
nitrogen $(77 \mathrm{~K}$ ) temperatures in a Hitachi-Perkin Elmer Model 556 spectrophotometer with the slit width set at 2 $\mathrm{nm}$. Washed bacteria from the fermenter were suspended in $50 \mathrm{mM}-\mathrm{Na}_{2} \mathrm{HPO}_{4} / \mathrm{KH}_{2} \mathrm{PO}_{4}, \mathrm{pH} 7.0$ prior to measurement of spectra. Reduced minus oxidized difference spectra were obtained by reduction of one sample with a few grains of $\mathrm{Na}_{2} \mathrm{~S}_{2} \mathrm{O}_{4}$ and ensuring that the sample in the reference cuvette was fully oxidized by addition of either one drop of $\mathrm{H}_{2} \mathrm{O}_{2}$ or a few grains of $\mathrm{K}_{3} \mathrm{Fe}(\mathrm{CN})_{6}$. Spectra at room temperature were measured in quartz cuvettes with a $10 \mathrm{~mm}$ pathlength. Reduced plus $\mathrm{CO}$ minus reduced spectra were obtained by the reduction of the contents of both cuvettes with $\mathrm{Na}_{2} \mathrm{~S}_{2} \mathrm{O}_{4}$ and then bubbling a stream of $\mathrm{CO}$ through the sample cuvette for $5 \mathrm{~min}$. The $\mathrm{CO}$ treated cuvette was left in the dark for $10 \mathrm{~min}$ before the spectrum was recorded.

Difference spectra at $77 \mathrm{~K}$ were measured with washed bacterial samples resuspended in $50 \mathrm{~mm}$-phosphate buffer, pH 7.0, containing $0.8 \mathrm{M}$-sucrose. Samples in cuvettes of $1 \mathrm{~mm}$ pathlength were rapidly cooled in liquid nitrogen and spectra were recorded at $77 \mathrm{~K}$.

Determination of cytochrome concentrations. Cytochrome $d$ concentration was tentatively estimated from room temperature reduced minus oxidized difference spectra from the difference in absorbance between the peak at 630 $\mathrm{nm}$ and the trough at $648 \mathrm{~nm}$. Total cytochrome $b$ concentration was estimated in the same way from the difference in absorbance between $560 \mathrm{~nm}$ and $579 \mathrm{~nm}$. Since the cytochrome $d$ and $o$ peaks overlapped in reduced plus $\mathrm{CO}$ minus reduced difference spectra, the concentration of cytochrome $o$ was calculated from the difference in absorbance between $558 \mathrm{~nm}$ and $572 \mathrm{~nm}$ in such spectra (Poole \& Haddock, 1975). This assumes that cytochrome $o$ is the only $b$-type cytochrome reacting with carbon monoxide (Castor \& Chance, 1959).

Measurements of $\mathrm{H}^{+} / \mathrm{O}$ ratios. $\mathrm{H}^{+} / \mathrm{O}$ ratios were measured essentially as described by Drozd (1976). After washing in $1 \mathrm{~mm}$-Tris $\mathrm{HCl} / 140 \mathrm{mM}-\mathrm{KCl}$ buffer ( $\mathrm{pH} \mathrm{7.0)}$ ), bacteria were resuspended in the same buffer to a concentration of $9 \mathrm{mg}$ dry wt ml-1 The resuspended bacteria were not starved before measurement of $\mathrm{H}^{+} / \mathrm{O}$ ratios. When included in the suspension medium, the concentration of L-lactate (lithium salt) was $10 \mathrm{mM}$.

\section{RESULTS}

Growth yields

Enterobacter aerogenes NCTC 10336 was grown in chemostat culture at a dilution rate of $0 \cdot 1 \mathrm{~h}^{-1}$ under carbon- (lactate) or oxygen-limited growth conditions in the presence and absence of low concentrations of potassium cyanide. In those cultures that were supplemented with cyanide, the concentration of cyanide measured in the culture filtrate under steady state conditions was approximately $3 \mu \mathrm{M}$ in both the oxygen- and carbon-limited cultures. No study was made of possible enzymic cyanide detoxifying mechanisms or any non-specific binding of cyanide to the cells, which would account for the reduction in the cyanide concentration from $200 \mu \mathrm{M}$ (the concentration in the inflowing medium) to $3 \mu \mathrm{M}$. However, a high concentration of hydrogen cyanide was detected in the effluent gas stream and it was evident that most of the inhibitor was lost in this way. The observed molar growth yields at a dilution rate of $0 \cdot 1 \mathrm{~h}^{-1}$ are shown in Table 1 . The $Y_{\mathrm{O}_{2}}$ fell by $40 \%$ when the culture conditions were changed from a carbonand energy-limited environment to one in which growth was limited by the availability of oxygen. A similar decrease $(50 \%)$ was observed when cyanide was fed to a carbon-limited culture. However, cyanide did not cause a decrease in the $Y_{\mathrm{O}_{2}}$ obtained in oxygen-limited cultures. The molar growth yield from lactic acid $\left(Y_{\text {lac }}\right)$ under oxygen-limited conditions was $20 \%$ lower than in the carbon-limited cultures. This decrease was accompanied by the appearance of $0.78 \mathrm{~g}$ lactate $1^{-1}$ in the culture filtrate, but the carbon balance in Table 2 indicated that there was no significant accumulation of soluble carbonaceous products in the culture supernatant. Cyanide-treated, carbon- and oxygen-limited cultures also exhibited large reductions in $Y_{\text {lac }}$. Under carbon limitation, there was no accumulation of lactate or other carbon based product(s) in the culture supernatant. However, in the cyanide-treated, oxygenlimited culture, there was a further decrease in $Y_{\text {lac }}$, with a concomitant accumulation of extracellular lactate and acetate.

The specific rates of substrate utilization and product formation (Table 1) reflect the decreases in molar growth yields. The effects of cyanide and oxygen-limitation were to stimulate the $q_{\mathrm{O}_{2}}, q_{\mathrm{CO}_{2}}$ and $q_{\mathrm{lac}}$ above their carbon-limited values.

\section{Apparent $K_{\mathrm{m}}$ values for $\mathrm{D}-$ and $\mathrm{L}$-lactate oxidation}

The apparent $K_{\mathrm{m}}$ values for the oxidation of both D- and L-lactate by harvested cells of $E$. aerogenes did not significantly change with growth limitation. The apparent $K_{\mathrm{m}}$ values were all 
Table 1. Effect of oxygen limitation and growth in the presence of cyanide on the molar growth yields $(Y)$ and specific rates of substrate utilization and product formation $(q)$ in chemostat cultures of E. aerogenes grown at a dilution rate of $0 \cdot 1 h^{-1}, p H 7 \cdot 0,30^{\circ} \mathrm{C}$

The results show the mean values \pm s.D.

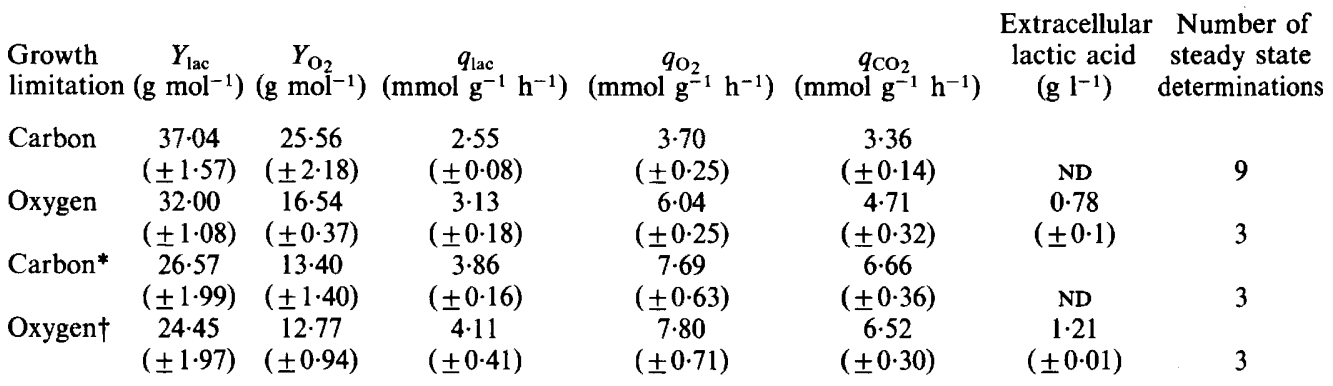

ND, Not detected.

* Concentration of cyanide measured in culture supernatant was $3 \cdot 3( \pm 1 \cdot 5) \mu \mathrm{M}$; cyanide was present in the inflowing medium.

$\dagger$ Concentration of cyanide measured in culture supernatant was $2.7( \pm 1 \cdot 2) \mu \mathrm{M}$; cyanide was present in the inflowing medium.

Table 2. Carbon balances based on lactate metabolized for chemostat cultures of $E$. aerogenes (Table 1) grown at a dilution rate of $0 \cdot 1 \mathrm{~h}^{-1}, \mathrm{pH} 7 \cdot 0,30^{\circ} \mathrm{C}$

The results show the mean values \pm S.D.

Incorporation of lactic acid

\begin{tabular}{|c|c|c|c|c|c|}
\hline \multirow{2}{*}{$\begin{array}{l}\text { Growth } \\
\text { limitation }\end{array}$} & \multicolumn{3}{|c|}{ carbon $(\%)$} & \multirow{2}{*}{$\begin{array}{c}\text { Carbon } \\
\text { recovery }(\%)\end{array}$} & \multirow{2}{*}{$\begin{array}{c}\text { Number of } \\
\text { steady state } \\
\text { determinations }\end{array}$} \\
\hline & Cells & Carbon dioxide & Cell product(s) & & \\
\hline Carbon & $\begin{array}{c}46.3 \\
( \pm 1.4)\end{array}$ & $\begin{array}{c}44.0 \\
( \pm 2.5)\end{array}$ & $\begin{array}{c}4.0 \\
( \pm 0.3)\end{array}$ & $\begin{array}{c}94.3 \\
( \pm 3.7)\end{array}$ & 9 \\
\hline Oxygen & $40 \cdot 0$ & $50 \cdot 2$ & $6 \cdot 4$ & $96 \cdot 6$ & \\
\hline & $( \pm 1 \cdot 4)$ & $( \pm 0 \cdot 9)$ & $( \pm 2-0)$ & $( \pm 1 \cdot 1)$ & 3 \\
\hline Carbon* & $\begin{array}{c}33 \cdot 7 \\
(+2 \cdot 1)\end{array}$ & $\begin{array}{c}57.4 \\
(+1.3)\end{array}$ & $\begin{array}{c}4.7 \\
(+0.7)\end{array}$ & $\begin{array}{r}95.8 \\
(+1.9)\end{array}$ & 3 \\
\hline Oxygen $†$ & $\begin{array}{c}30 \cdot 3 \\
( \pm 2 \cdot 4)\end{array}$ & $\begin{array}{c}53.0 \\
( \pm 2.7)\end{array}$ & $\begin{array}{c}17 \cdot 7 \\
( \pm 3 \cdot 7)\end{array}$ & $\begin{array}{c}101.0 \\
( \pm 2.9)\end{array}$ & 3 \\
\hline
\end{tabular}

* Concentration of cyanide measured in culture supernatant was $3.3( \pm 1.5) \mu \mathrm{M}$; cyanide was present in the inflowing medium.

$\dagger$ Concentration of cyanide measured in culture supernatant was $2 \cdot 7( \pm 1 \cdot 2) \mu \mathrm{M}$; cyanide was present in the inflowing medium.

in the range $20 \mu \mathrm{M}$ to $60 \mu \mathrm{M}$, which indicated that there was probably no change to a lower affinity lactate uptake system in cultures grown under oxygen-limitation with excess lactate.

\section{Effect of cyanide on the respiration rates of harvested bacteria}

The effect of cyanide on the oxidation of L-lactate by harvested bacteria that had been grown at a dilution rate of $0 \cdot 1 \mathrm{~h}^{-1}$ under carbon- and oxygen-limited conditions in the presence and absence of cyanide is shown in Fig. 1. The respiration of L-lactate by bacteria grown under carbon-limited conditions was the most sensitive to cyanide, with a $50 \%$ inhibition of the rate of oxygen uptake $\left(\mathrm{I}_{50}\right)$ given by $30 \mu \mathrm{M}$-cyanide. However, when oxygen was the growth limiting substrate, the resistance of the bacteria increased with an $\mathrm{I}_{50}$ of $250 \mu \mathrm{M}$-cyanide. The greatest change in cyanide sensitivity occurred when the bacteria were grown in the presence of low concentrations of cyanide. Under these circumstances, there was very little difference between the cyanide sensitivities of carbon-limited and oxygen-limited cells; in each case the $I_{50}$ increased to approximately $5 \mathrm{~mm}$. By changing the temperature of incubation, it was found that 


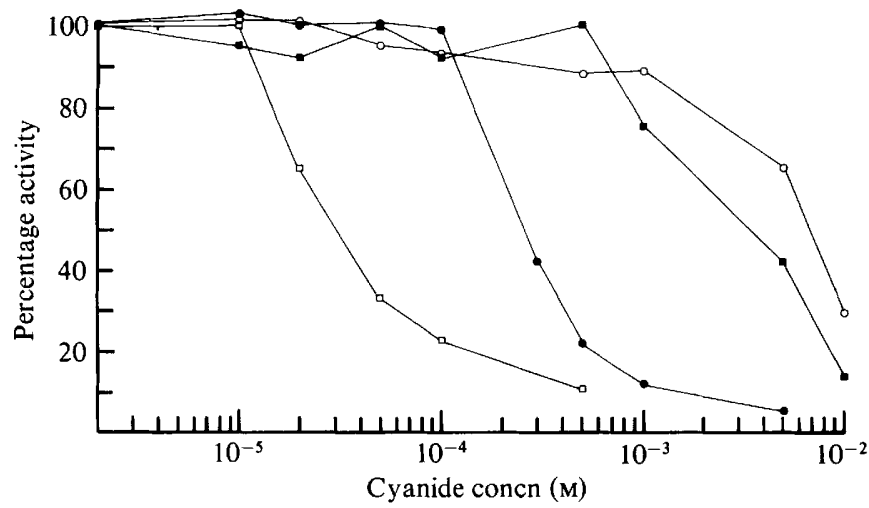

Fig. 1. Inhibition by cyanide of respiration in harvested cells of $E$. aerogenes oxidizing L-lactate. Bacteria were grown at a dilution rate of $0 \cdot 1 \mathrm{~h}^{-1}$ under the following nutrient limitations: $\square$, lactatelimited (10.00); $O$, oxygen-limited $(6 \cdot 30)$; $O$, lactate-limited in the presence of cyanide $(12 \cdot 19) ; \square$, oxygen-limited in the presence of cyanide (19.13). Respiration rates are expressed as a percentage of the uninhibited rate which is indicated above in parentheses [mmol $\left.\mathrm{O}_{2}(\mathrm{~g} \text { dry wt) })^{-1} \mathrm{~h}^{-1}\right]$.

the value of the uninhibited rate of respiration had no effect on the cyanide sensitivity of the bacteria over the range $6.9 \mathrm{mmol} \mathrm{O}_{2} \mathrm{~g}^{-1} \mathrm{~h}^{-1}$ to $14.7 \mathrm{mmol} \mathrm{O}_{2} \mathrm{~g}^{-1} \mathrm{~h}^{-1}$. For clarity the results have therefore been expressed in a percentage activity plot (cf. Linton et al., 1976). Similar results were obtained with bacteria oxidizing D-lactate.

\section{Room temperature cytochrome spectra}

Room temperature reduced minus oxidized difference spectra of intact cells of $E$. aerogenes grown under the different conditions are shown in Fig. 2. Each spectrum exhibits $\alpha$-absorption peaks at around $630 \mathrm{~nm}$ (cytochrome $d$ ), $595 \mathrm{~nm}$ (cytochrome $a_{1}$ ), and $560 \mathrm{~nm}$ (cytochrome $b$ ). In carbon-limited cells grown in the presence and absence of cyanide, the Soret peak was at 428 $\mathrm{nm}$, whereas in the corresponding oxygen-limited cells this peak was significantly broader and shifted to $434 \mathrm{~nm}$.

Cytochrome components were also tentatively identified on the basis of their reactivity with carbon monoxide. The CO-difference spectra (Fig. 3) of carbon-limited bacteria grown in the presence and absence of cyanide indicate that the major $\mathrm{CO}$-binding pigment in each case was probably cytochrome $o$ (absorption maxima at $430 \mathrm{~nm}$ and $558 \mathrm{~nm}$ ). In contrast, the CO spectrum of oxygen-limited bacteria (Fig. 3) shows absorption minima at $448 \mathrm{~nm}$ and $618 \mathrm{~nm}$ which we believe are due to cytochrome $d$, although the former could possibly be caused by cytochrome $a_{1}$. The shoulder at $430 \mathrm{~nm}$ corresponds to cytochrome $o$. The CO spectrum of oxygen-limited bacteria grown in the presence of cyanide is similar. Absorption minima at 443 $\mathrm{nm}$ and $615 \mathrm{~nm}$ are still present, together with troughs at $429 \mathrm{~nm}$ and $558 \mathrm{~nm}$ which are indicative of cytochrome $o$.

Cytochrome concentrations were calculated as described in Methods and are shown in Table 3. There was a large increase in the concentration of cytochrome $d$ in carbon-limited bacteria when cyanide was included in the growth medium. This was even more pronounced in oxygenlimited cultures grown in the presence or absence of cyanide. Bacteria grown under these conditions also contained somewhat higher concentrations of cytochrome $b$ compared with those in carbon-limited bacteria. There was also a slight increase in the concentration of cytochrome $o$ when carbon-limited cells were grown in the presence of cyanide but its concentration was less under oxygen-limited growth conditions than in the lactate-limited cultures ( \pm cyanide). Concentrations of cytochrome $a_{1}$ are not included in Table 3 because they could not be estimated with sufficient accuracy. However, from estimates of the peak heights at 590 to $600 \mathrm{~nm}$ there did appear to be a slight increase in the concentration of cytochrome $a_{1}$ in cells grown under oxygen limitation although we would not like to place great confidence in this observation (Fig. 2). 


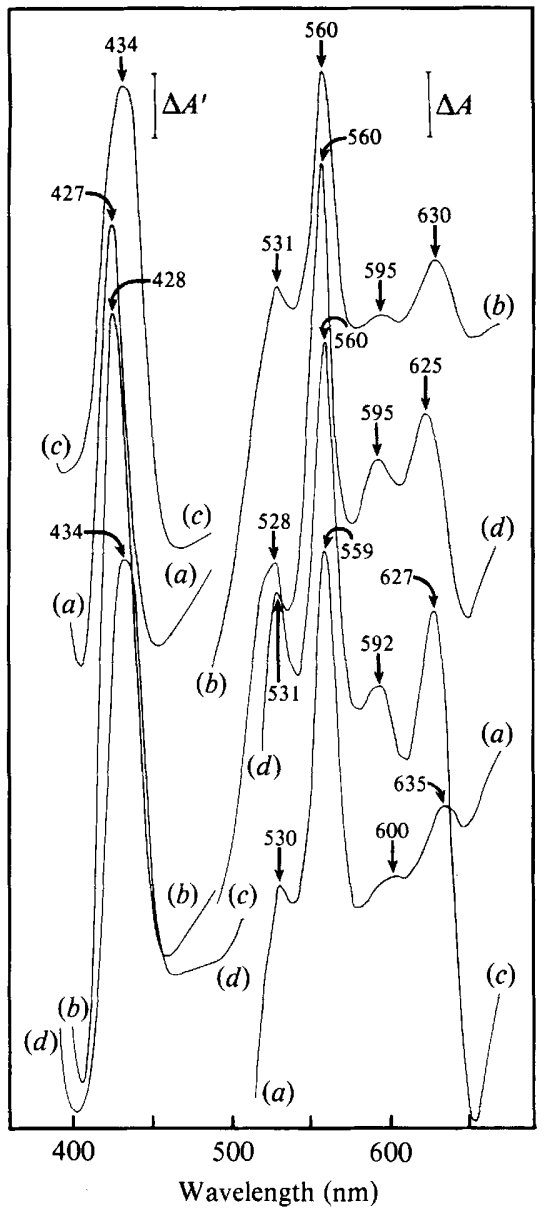

Fig. 2.

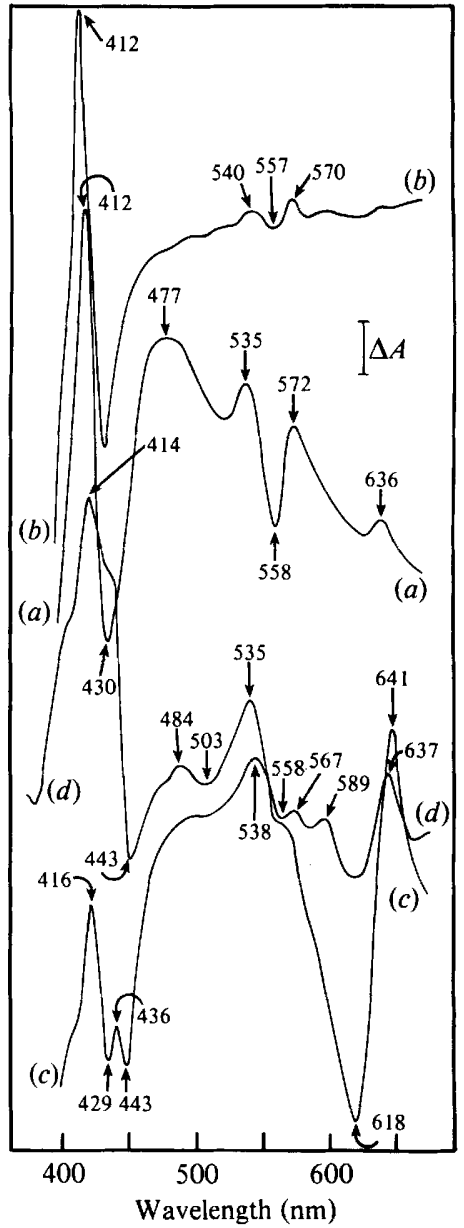

Fig. 3.

Fig. 2. Room temperature difference spectra of intact cells of $E$. aerogenes grown at a dilution rate of $0 \cdot 1 \mathrm{~h}^{-1} . \Delta A$ and $\Delta A^{\prime}$ represent the respective absorbance scales, where $\Delta A^{\prime}$ is for the Soret region (400 to

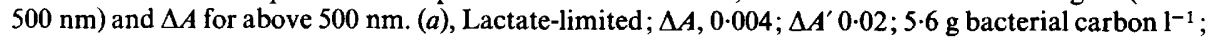

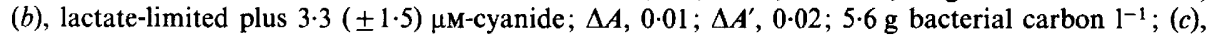
oxygen-limited; $\Delta A, 0 \cdot 02 ; \Delta A^{\prime}, 0 \cdot 04 ; 20.8 \mathrm{~g}$ bacterial carbon $\mathrm{l}^{-1} ;(d)$ oxygen-limited plus $2 \cdot 7( \pm 1 \cdot 5) \mu \mathrm{M}-$ cyanide; $\Delta A, 0.01 ; \Delta A^{\prime}, 0 \cdot 04 ; 7.2 \mathrm{~g}$ bacterial carbon $1^{-1}$.

Fig. 3. Room temperature CO-difference spectra of intact cells of $E$. aerogenes grown at a dilution rate of $0.1 \mathrm{~h}^{-1}$. The contents of both cuvettes were reduced with a few grains of $\mathrm{Na}_{2} \mathrm{~S}_{2} \mathrm{O}_{4}$ and then the contents of the sample cuvettes were reacted with carbon monoxide. $\Delta \boldsymbol{A}$ represents the absorbance scale as below. (a), Lactate-limited; $\Delta A, 0.005 ; 12.8 \mathrm{~g}$ bacterial carbon $\mathrm{l}^{-1} ;(b)$, lactate-limited plus $3 \cdot 3( \pm 1 \cdot 5)$ $\mu \mathrm{M}$-cyanide; $\Delta A, 0.01 ; 5.6 \mathrm{~g}$ bacterial carbon $\mathrm{H}^{-1} ;(c)$, oxygen-limited $\Delta A, 0.01 ; 20.8 \mathrm{~g}$ bacterial carbon $1^{-1} ;(d)$, oxygen-limited plus $2 \cdot 7( \pm 1 \cdot 5) \mu \mathrm{M}$-cyanide; $\Delta A, 0 \cdot 01 ; 7 \cdot 2 \mathrm{~g}$ bacterial carbon $1^{-1}$.

\section{Cytochrome spectra at liquid nitrogen temperatures}

Spectra at $77 \mathrm{~K}$ resolved the cytochrome peak tentatively assigned to cytochrome $b$ into a number of components (Fig. 4). Carbon-limited bacteria possessed a single broad cytochrome $b$ peak at $553 \mathrm{~nm}$ with a shoulder at $547 \mathrm{~nm}$ possibly indicative of a $c$-type cytochrome. However, this observation requires confirmation from pyridine-haemochrome spectra. In bacteria grown in the presence of cyanide, irrespective of the substrate limitation, the cytochrome $b$ peak was resolved into two components with peaks at $557 \mathrm{~nm}$ and $560 \mathrm{~nm}$. The low-temperature spectrum of oxygen-limited bacteria also showed a splitting of the cytochrome $b$ peak into two components 
Table 3. Cytochrome concentrations in cells of $E$. aerogenes grown at a dilution rate of $0 \cdot 1 \mathrm{~h}^{-1}$, pH $7 \cdot 0,30^{\circ} \mathrm{C}$

The resolution of the $b$-type cytochromes into separate peaks in spectra at $77 \mathrm{~K}$ is shown. $(+)$ indicates the presence of an observable peak, whereas $(-)$ indicates that the component was not observed. See the text for comments on cytochrome $a_{1}$ concentrations.

Cytochrome concentration

$10^{4} \times \Delta \boldsymbol{A}\left[\mathrm{g} \text { bacterial carbon }(1)^{-1}\right]^{-1}$

\begin{tabular}{|c|c|c|c|c|c|c|c|c|}
\hline $\begin{array}{l}\text { Growth } \\
\text { limitation }\end{array}$ & $d$ & $o$ & $b$ & $a_{1}$ & $b_{553}$ & $b_{555}$ & $b_{557}$ & $b_{560}$ \\
\hline Carbon & $2 \cdot 14$ & $7 \cdot 62$ & $39 \cdot 82$ & + & + & - & - & - \\
\hline Carbon* & $21 \cdot 88$ & $9 \cdot 82$ & 71.43 & + & - & - & + & + \\
\hline Oxygen & 76.44 & 6.97 & $55 \cdot 77$ & ++ & - & + & + & - \\
\hline Oxygent & $44 \cdot 44$ & $3 \cdot 13$ & $77 \cdot 78$ & ++ & - & - & + & + \\
\hline
\end{tabular}

* Concentration of cyanide measured in culture supernatant was $3.3( \pm 1.5) \mu \mathrm{M}$; cyanide was present in the inflowing medium.

$\dagger$ Concentration of cyanide measured in culture supernatant was $2.7( \pm 1 \cdot 2) \mu \mathrm{M}$; cyanide was present in the inflowing medium.

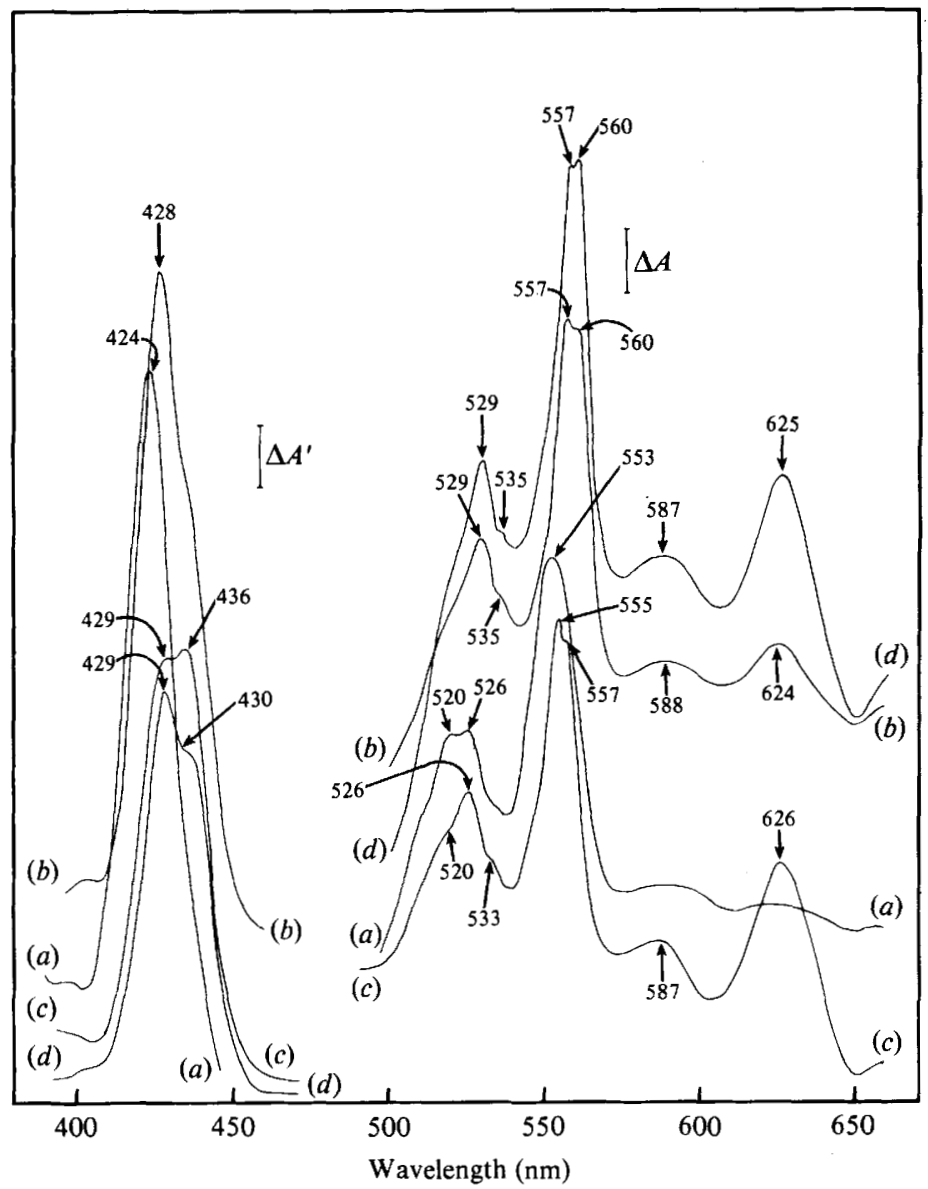

Fig. 4. Low temperature $\mathrm{Na}_{2} \mathrm{~S}_{2} \mathrm{O}_{4}$-reduced minus $\mathrm{H}_{2} \mathrm{O}_{2}$-oxidized difference spectra of intact cells of $E$. aerogenes grown at a dilution rate of $0 \cdot 1 \mathrm{~h}^{-1} . \triangle A$ represents the absorbance scale above $500 \mathrm{~nm}$ while $\Delta A^{\prime}$ represents the absorbance scale for the Soret region $(400$ to $500 \mathrm{~nm})$. (a), Lactate-limited; $\Delta A, 0 \cdot 02$; $\Delta A^{\prime}, 0.04 ; 12.8 \mathrm{~g}$ bacterial carbon $1^{-1} ;(b)$, lactate-limited plus $3.3( \pm 1.5) \mu \mathrm{M}$-cyanide; $\Delta A, 0 \cdot 02 ; \Delta A^{\prime}$,

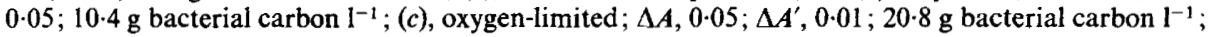
$(d)$, oxygen-limited plus $2.7( \pm 1.5) \mu \mathrm{M}$-cyanide; $\Delta A, 0.02 ; \Delta A^{\prime}, 0.01 ; 9.6 \mathrm{~g}$ bacterial carbon $1^{-1}$. 
exhibiting absorption maxima at $557 \mathrm{~nm}$ and $555 \mathrm{~nm}$. A shoulder at $550 \mathrm{~nm}$ was apparent in bacteria grown under the last three conditions. In the Soret region, carbon-limited cells had a single absorption peak at $424 \mathrm{~nm}$ due to $b$-type cytochromes [Fig. 4, trace (a)]. The shift in the absorption maximum to a slightly lower wavelength may have been due to interference from cytochrome $c$. Traces $(b),(c)$ and $(d)$ (Fig. 4) possess in addition to a peak at $429 \mathrm{~nm}$, another peak or shoulder at $436 \mathrm{~nm}$ which may be attributed to cytochrome $d$ or $a_{1}$.

\section{$\mathrm{H}^{+} / \mathrm{O}$ ratios}

$\mathrm{H}^{+} / \mathrm{O}$ ratios were measured to detect any changes in the efficiency of oxidative phosphorylation of the organism when grown under different steady state conditions. However the results, obtained using unstarved bacterial cells were very variable and did not clearly indicate any changes in the number of sites of phosphorylation.

An important finding was that cyanide did not behave as an uncoupler in these experiments. Unlike dinitrophenol, which in low concentrations caused a rapid collapse of the proton pulse, concentrations of up to $10 \mathrm{mM}-\mathrm{KCN}$ at $\mathrm{pH} 7.0$ had no measurable effect on the rate of decay in $\mathrm{pH}$ after a burst of respiration.

\section{DISCUSSION}

In comparison with lactate-limited cultures, lower $Y_{\mathrm{O}_{2}}$ values were obtained for lactatelimited cultures grown in the presence of cyanide and for oxygen-limited cultures ( \pm cyanide) (Table 1). The similarity of the $Y_{\mathrm{O}_{2}}$ values under the last three growth conditions suggests that both low oxygen tension and cyanide may cause similar physiological changes in the bacteria. However, decreases in growth yields over the carbon-limited figures could be due to a variety of reasons, for example: (a) large amounts of overflow metabolites produced under oxygenlimitation or in the presence of cyanide; (b) cyanide behaving as an uncoupler of oxidative phosphorylation and causing a rapid decay of the protonmotive force; (c) an increased maintenance requirement or death rate of the culture; (d) a decrease in the efficiency of oxidative phosphorylation in the bacteria as a result of a diversion of electron flow to an alternative cytochrome oxidase via a respiratory pathway with a lower efficiency of energy transduction and (e) the activity of an energy-wasting futile cycle produced in the presence of cyanide.

Decrease in $Y_{\mathrm{O}_{2}}$ values caused by production of overflow metabolites is an unlikely explanation since no metabolites were detected in oxygen-limited and cyanide-fed carbonlimited cultures and only a small amount of acetate was detected in the supernatant from oxygen-limited cultures grown in the presence of cyanide.

Cyanide did not decrease the growth yields by diminishing the transmembrane proton gradient since in proton pulse experiments, concentrations of up to $10 \mathrm{~mm}$-cyanide, at the growth $\mathrm{pH}$ of $7 \cdot 0$, had no effect on the decay rate of the pulse.

Ideally, experiments should have been carried out at a number of dilution rates to permit calculation of true molar growth yields $\left(Y_{\mathrm{O}_{2}}^{\max }\right.$ and $\left.Y_{\mathrm{lac}}^{\max }\right)$ and the maintenance energy requirement (Pirt, 1965). A large increase in maintenance energy brought about by oxygen limitation or cyanide may have contributed to the observed decreases in $Y_{\mathrm{O}_{2}}$ and $Y_{\mathrm{lac}}$. In mathematical terms, a high death rate in a culture is formally equivalent to a high maintenance value (Drozd et al., 1978). However, a significant increase in the death rate caused by cyanide was not apparent since there was no build up of lysis products in the supernatant from cultures fed with cyanide (Table 2).

Thus, the observed decreases in $Y_{\mathrm{O}_{2}}$ under oxygen limitation and carbon limitation in the presence of cyanide could be due to a decrease in the efficiency of respiratory chain energy conversion. Such a change may involve diversion of electron flow along the electron transport chain to a cytochrome oxidase to which cyanide binds less readily and which may have a higher affinity for oxygen. If electron transport to oxygen via this alternative oxidase is associated with a lower efficiency of energy transduction, i.e. a lower $\mathrm{H}^{+} / \mathrm{O}$ ratio (Meyer \& Jones, 1973), the respiration rate would have to increase to maintain the same rate of production of ATP. 
Room temperature difference spectra revealed large increases in the concentration of a cytochrome oxidase tentatively identified as a $d$-, or possibly $a_{1}$ type in bacteria grown oxygenlimited or lactate-limited in the presence of cyanide (Table 3 ). In other bacteria, the functional replacement of an $o$-type cytochrome oxidase by one of the $d$-type is associated with a decrease in the efficiency of oxidative phosphorylation, and hence of growth yield (Meyer \& Jones, 1973). Pudek \& Bragg (1974) found a correlation between cyanide resistant respiration and the concentration of cytochrome $d$ in $E$. coli.

Respiratory resistance to cyanide $\left(\mathrm{I}_{50}\right)$ in $E$. aerogenes grown under the four conditions did not show a complete correlation with the absolute concentration of cytochrome $d$ in the bacteria. Oxygen-limited bacteria containing a higher concentration of cytochrome $d$ showed a smaller increase in cyanide resistance over lactate-limited cells than bacteria grown under lactatelimited conditions in the presence of cyanide (Fig. 1, Table 3 ). The concentration of cytochrome $o$ did not increase significantly above that found in lactate-limited bacteria when cyanide was added to the growth medium and in fact decreased when oxygen was the growth limiting substrate. It probably has a high affinity for KCN (Pudek \& Bragg, 1974) which would rule out any role it may have in cyanide resistance. Cytochrome $a_{1}$ was found in low concentrations under all growth conditions, but in slightly higher concentrations under oxygen-limitation in the presence and absence of cyanide. In Acetobacter species, cytochrome $a_{1}$ serves as a terminal oxidase (Castor \& Chance, 1959; Meyer \& Jones, 1973) but it has been suggested that cytochrome $a_{1}$ is not kinetically competent to support observed respiration rates in $E$. coli (Haddock et al., 1976). Assuming that cytochromes $o$ and $a_{1}$ from $E$. aerogenes behave in a similar manner, cytochrome $d$ probably plays a leading role in cyanide-resistant respiration. Concomitant with increases in the concentration of cytochrome $d$, were changes in the spectra in the 550 to $560 \mathrm{~nm}$ region. Carbon-limited cultures possessed a broad peak with an absorption maximum of $553 \mathrm{~nm}$ in difference spectra measured at $77 \mathrm{~K}$. The peak was not resolvable into components. In the more cyanide-tolerant oxygen-limited cells, two peaks were evident with absorption maxima at $553 \mathrm{~nm}$ and $557 \mathrm{~nm}$. The absorption maxima at $553 \mathrm{~nm}$ for these two cultures suggest the presence of $c$-type cytochromes (Shipp, 1972) but this needs to be confirmed by pyridine haemochrome spectra. The most cyanide-resistant bacteria, i.e. those grown in its presence under both carbon and oxygen limitation, contained two different $b$-type cytochromes; $b_{557}$ (also produced under oxygen-limitation) and $b_{560}$. Reid \& Ingledew (1980) have recently purified the haem $d$ containing cytochrome oxidase from $E$. coli and found it to contain both cytochromes $b$ and $d$. Cytochrome $b_{555}$ and $b_{558}$ were resolved spectrally and the complex was envisaged as containing equimolar amounts of $b$ and $d$ such that it contained four haem redox centres.

It is possible that a cytochrome $b, d$ complex also exists in $E$. aerogenes with electron flow to oxygen via this oxidase complex being associated with a lower $\mathrm{P} / \mathrm{O}$ ratio than the electron pathway involving cytochrome $o$. If the complex had a higher affinity for oxygen, this would explain its production under low dissolved oxygen tensions with a corresponding decrease in $Y_{\mathrm{O}_{2}}$. Similarly, a modification of the complex manifest by slight changes in the wavelengths of maximal absorbance of the $\alpha$ peaks of the $b$-type cytochromes, may be responsible for the increased cyanide resistance of the oxidase. This modified complex may be induced during growth in the presence of cyanide and may account for the reduced $Y_{\mathrm{O}_{2}}$ values.

The results may be of practical significance in relation to the biotreatment of aqueous wastes containing cyanide. The decrease in growth yields caused by cyanide would give diminished sludge yields but would result in a higher specific oxygen requirement for growth. It remains to be seen if cyanide, or similar compounds, have the same effect on the aerobic growth of other micro-organisms. It would be interesting to look at the effects of cyanide on the anaerobic (fermentative) growth of micro-organisms.

N. Porter thanks the SERC for the provision of a C.A.S.E. award. We would like to thank Dr C. J. Knowles for many useful comments and criticisms. 


\section{REFERENCES}

ARIMA, K. \& OKA, T. (1965). Cyanide resistance in Achromobacter. I. Induced formation of cytochrome $a_{2}$ and role in cyanide-resistant respiration. Journal of Bacteriology 90, 734-743.

AshCrofT, J. R. \& HadDoCK, B. A. (1975). Synthesis of alternative membrane-bound redox carriers during aerobic growth of Escherichia coli in the presence of potassium cyanide. Biochemical Journal 148, 349352.

Castor, L. \& Chance, B. (1959). Photochemical determinations of the oxidases of bacteria. Joumal of Biological Chemistry 234, 1587-1592.

Deans, D. R., Huckle, M. T. \& Peterson, R. M. (1971). A new column system for isothermal gas chromatographic analysis of light gases $\left(\mathrm{H}_{2}, \mathrm{O}_{2}, \mathrm{~N}_{2}\right.$, $\mathrm{CO}, \mathrm{CH}_{4}, \mathrm{CO}_{2}, \mathrm{C}_{2} \mathrm{H}_{2}, \mathrm{C}_{2} \mathrm{H}_{6}$ and $\mathrm{C}_{2} \mathrm{H}_{2}$ ) employing a column switch technique. Chromatographia 4, 279285.

DiXon, M. \& WeBB, E. C. (1964). In Enzymes, pp. 337341. London: Longmans.

DRozD, J. W. (1976). Energy coupling and respiration in Nitrosomonas europaea. Archives of Microbiology 110, 257-262.

Drozd, J. W., Linton, J. D., Downs, J. \& StephensoN, R. J. (1978). An in situ measurement of the specific lysis rate in continuous cultures of Methylococcus sp (NCIB 11083) grown on methane. FEMS Microbiology Letters 4, 311-314.

EPSTEIN, J. (1947). Estimation of microquantities of cyanide. Analytical Chemistry 19, 272-274.

Haddock, B. A., Downie, J. A. \& GaRland, P. B. (1976). Kinetic characterisation of the membranebound cytochromes of Escherichia coli grown under a variety of conditions by using a stopped flow dual wavelength spectrophotometer. Biochemical Journal 154, 285-294.

Jones, G. L. \& Carrington, E. G. (1972). Growth of pure and mixed cultures of micro-organisms concerned in the treatment of carbonization waste liquors. Journal of Applied Bacteriology 35, 395-404.

KNOWLES, C. J. (1976). Microorganisms and cyanide. Bacteriological Reviews 40, 652-680.

Linton, J. D., Harrison, D. E. F. \& Bull, A. T. (1976). The effect of rate of respiration on sensitivity to cyanide and carbon monoxide in Beneckea natriegens grown in batch and continuous culture. FEBS Letters 64, 358-363.

MaXTeD, J. \& WAYNE-SMith, R. N. (1974). A novel shaft bearing housing for laboratory-scale fermenters. Biotechnology and Bioengineering 16, 293-294.

MEYER, D. J. \& JONES, C. W. (1973). Reactivity with oxygen of bacterial cytochrome oxidases $a_{1}, a a_{3}$ and o. FEBS Letters 33, 101-105.

Møller, V. (1954). Diagnostic use of the Braun KCN test within the Enterobacteriaceae. Acta pathologica et microbiologica scandinavica 34, 115-126.

Munson, T. E. (1974). Improved KCN medium. Applied Microbiology 27, 262-263.

OKA, T. \& ARIMA, K. (1965). Cyanide-resistance in Achromobacter. II. Mechanisms of cyanide-resistance. Journal of Bacteriology 90, 744-747.

PIRT, S. J. (1965). The maintenance energy of bacteria in growing cultures. Proceedings of the Royal Society B163, 224-231.

Poole, R. K. \& Haddock, B. A. (1975). Effects of sulphate-limited growth in continuous culture on the electron transport chain and energy conservation in Escherichia coli K12. Biochemical Journal 152, 537546.

PORTER, N. (1979). Studies of cyanide-resistance in Enterobacter aerogenes and other Enterobacteriaceae. Ph.D. thesis, University of Kent, Canterbury, Kent, U.K.

Porter, N. \& Knowles, C. J. (1979). Cyanideresistant growth in Citrobacter freundii and other Enterobacteriaceae. FEMS Microbiology Letters 5, 323-326.

Pudex, M. R. \& BRaGG, P. D. (1974). Inhibition by cyanide of the respiratory chain oxidase of Escherichia coli. Archives of Biochemistry and Biophysics 164, $682-693$.

ReID, G. A. \& INGLeDEW, W. J. (1980). The purification of a respiratory oxidase complex from Escherichia coli. FEBS Letters 109, 1-4.

SHIPP, W. S. (1972). Absorption bands of multiple $b$ and $c$ cytochromes in bacteria detected by numerical analysis of absorption spectra. Archives of Biochemistry and Biophysics 150, 482-488. 